\title{
Electricity production by intermittent renewable sources: a synthesis of French and German studies
}

\author{
D. Grand ${ }^{1}$, Ch. Le Brun ${ }^{1, a}$, R. Vidil ${ }^{1}$, and F. Wagner ${ }^{2, b}$ \\ 1 GIRE, Grenoble, France \\ 2 Max-Planck-Institut für Plasmaphysik, Greifswald, Germany
}

Received: 13 April 2016 / Revised: 27 July 2016

Published online: 22 September 2016

(C) The Author(s) 2016. This article is published with open access at Springerlink.com

\begin{abstract}
Wind and solar electricity is produced without direct $\mathrm{CO}_{2}$ emissions. However, the introduction of this electricity in the grid is delicate due to the intermittent character of its sources. Wind and solar production is characterized by multiple, strong variations in the electric power. These variations put stress on the grid where the total production of electricity must always be equal to the consumption. We present a synthesis of five studies conducted for Germany and France with different assumptions of electricity mixes, all with large shares of wind and solar power. These mixes are subjected to the dynamics of wind and solar production as recorded in 2010 (Germany), 2012 and 2013 (Germany and France). Common structural trends are exhibited when the results of simulations (instantaneous power distributions and average annual values) are expressed as a percentage of the annual reduced load to be produced by these intermittent energies. We focus on the evaluation of these trends and the resulting constraints on the grid. The results obtained make it possible to anticipate the problems brought about by a large share of renewable intermittent energies in the production of electricity. They show the need for backup production in order to complement the intermittent sources. This leads to $\mathrm{CO}_{2}$ emissions unless storage systems of large capacity are available.
\end{abstract}

World electricity production relies mainly on fossil fuels and, consequently, is a big contributor to $\mathrm{CO}_{2}$ emissions. Electricity use is growing and will continue to grow, as more recent applications develop, e.g. internet and electric cars. In order to reduce their carbon footprint, many countries encourage and subsidize the development of electricity production from wind and solar photovoltaic energy sources. After construction of their infrastructure, both are free of direct emission of $\mathrm{CO}_{2}$ while operating. However, their production depends directly on intermittent fluxes: solar irradiation and wind, caused by the rotation of the earth and the thermodynamics of the atmosphere. Constraints arise from these intermittent (periodic and stochastic) productions and from the present impossibility to store electricity in large quantities. When available, storage is not direct but is linked to conversion to another form of energy and thus requires two transformations, each with losses. The management of electricity in the grid requires the equilibrium of production and consumption at all times. Any imbalance results in variations of the voltage or frequency of the electric power that can be detrimental to the consumer and even lead to power outages. Thus, power variations must be studied, known and managed, before large quantities of intermittent energy can be injected into the grid.

In order to study these power variations, a method has been developed in ref. [1] based on the temporal evolutions of consumption and of wind and solar production during one year. After a brief summary of the method, we present and compare the results obtained from the data obtained in Germany in 2010 [1], 2012 [2], 2013 [3] and in France in 2012 [4] and 2013 [3].

\footnotetext{
* Contribution to the Focus Point on "The Transition to Sustainable Energy Systems" edited by J. Ongena.

${ }^{a}$ e-mail: lebrun-chr@orange.fr

b e-mail: fritz.wagner@ipp.mpg.de
} 


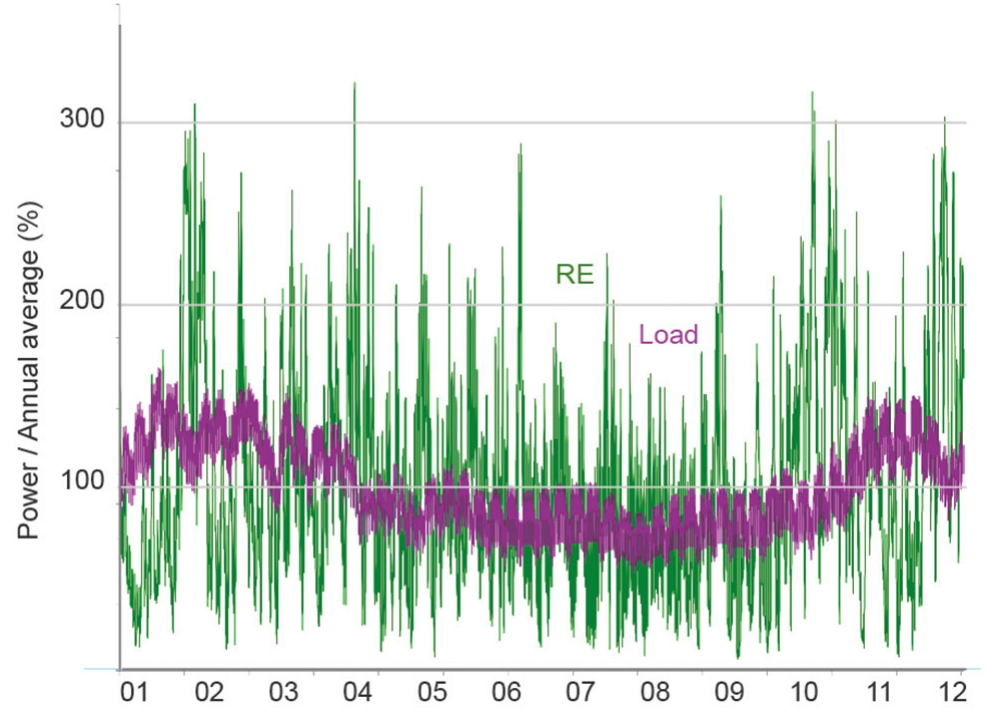

Fig. 1. Variation of consumption and added productions of wind and solar RE in France in 2013. Power values normalised by the averages of the year versus time (months).

\section{Position of the problem}

An electricity grid operator balances the production with the load in a country by collecting and adding the production of controlled sources. The operator selects the sources depending on their availability and market price to balance the time-variable power consumed. Sometimes equilibrium is achieved through exchanges with neighboring countries. Wind and solar production brings a new source of variability that must be handled by the operator. Although the amount of power produced by these sources cannot always be controlled, they are introduced into the grid first because of renewable energy purchase obligations.

The consequences of intermittency in electrical production can be fully appreciated only if the data used in the study are those of a given year in a given country. The stochastic behavior of production, the biggest problem, would be smoothed out and leveled off if productions from different years were averaged. Each year, chronological series are published for electrical consumption and for the production from the different sources (hydraulic, fossil, nuclear, wind, solar, etc.) in most of the countries of Europe. They give the recorded values of power at time intervals of one hour, $30 \mathrm{~min}$ or $15 \mathrm{~min}$, depending on the country. Figure 1 shows the values recorded in France in 2013 for consumption and total power from wind and solar PV production, hereafter abbreviated as RE (for Renewable intermittent Energy). Both curves are dimensionless: the instantaneous power of each curve is divided by its average value over the year (see table 1).

There is a striking difference between the two curves. On the one hand, consumption, or load, varies daily and weekly by less than $30 \%$ of the monthly average. On the other hand, RE production (sum of wind and solar) varies in a stochastic way between $10 \%$ and $300 \%$ of its yearly average. This gives an insight into the difficulty to complement $\mathrm{RE}$ production with other means so that the total power is equal to the load as required by consumption. These difficulties appear today in Germany and Denmark and even lead to negative prices on the electricity market during periods of overproduction from wind [2].

Power duration curves facilitate the comparison of RE production to the load required by consumption. A duration curve can easily be obtained from the chronological series of the recorded power values by simply sorting the records in decreasing order. Each point on the curve corresponds to a recorded value of power measured along the ordinate. The abscissa of the point gives the proportion of the year with recorded power values superior to the value of the ordinate. The same can be done for each production form. Figure 2 presents the duration curves for Germany in 2012: a continuous curve for the load, and dotted curves for onshore wind (Won) and solar PV. Offshore wind production is much lower than the other two and its power is multiplied by 200 so that it can be seen on the graph. The load decreases regularly to a minimum, which is roughly half of the maximum. Onshore wind and solar PV decrease steeply following convex curves and fall to zero. Solar is zero during half of the year as expected (night time).

In ref. [1] a method is proposed to predict the size of the gap between the load (consumption) and RE production (wind and solar). It is based upon:

1) Assumption of a reference case defined by annual consumption and production of electrical energy and an assumed share of wind and solar in the mix. 
Table 1. Data from five reference studies: consumption, wind rated capacity and production, idem for solar PV, sum of RE production (wind and PV), annual reduced load of the reference case. (Figures in italic - TWh; figures in roman - GWy.)

\begin{tabular}{|c|c|c|c|c|c|c|c|}
\hline & $\begin{array}{l}\text { Consumption } \\
\qquad \begin{array}{c}\text { TWh } \\
\text { GWy }\end{array}\end{array}$ & $\begin{array}{c}\text { Wind } \\
\text { capacity } \\
\text { GW }\end{array}$ & $\begin{array}{c}\text { Wind } \\
\text { production } \\
\text { TWh } \\
\text { GWy }\end{array}$ & $\begin{array}{c}\text { PV } \\
\text { capacity } \\
\text { GW }\end{array}$ & $\begin{array}{c}\mathrm{PV} \\
\text { production } \\
\text { TWh } \\
\text { GWy }\end{array}$ & $\begin{array}{c}\mathrm{RE} \\
\text { production } \\
\text { TWh } \\
\text { GWy }\end{array}$ & $\begin{array}{c}\text { Reduced load } \\
\qquad \begin{array}{c}\text { TWh } \\
\text { GWy }\end{array}\end{array}$ \\
\hline Germany [1] & 588 & & 35.3 & & 13.4 & 48.7 & 562 \\
\hline 2010 & 67.2 & 28 & 4.03 & 16.8 & 1.53 & 5.56 & 64.2 \\
\hline Germany [2] & 583 & & 46.3 & & 31.3 & 77.7 & 500 \\
\hline 2012 & 66.6 & 30 & 5.28 & 32.4 & 3.57 & 8.86 & 57.1 \\
\hline Germany [3] & 632 & & 51.7 & & 31 & 82,7 & 453 \\
\hline 2013 & 72.1 & 34 & 5.90 & 32.1 & 3.54 & 9.44 & 51.7 \\
\hline France [4] & 532 & & 15.5 & & 4.03 & 19.3 & 201 \\
\hline 2012 & 60.7 & 7.4 & 1.77 & 3.5 & 0.46 & 2.23 & 23.1 \\
\hline France [3] & 548 & & 16.0 & & 4.5 & 20.5 & 193 \\
\hline 2013 & 62.5 & 7,8 & 1.83 & 4.0 & 0.51 & 2.34 & 22.1 \\
\hline
\end{tabular}

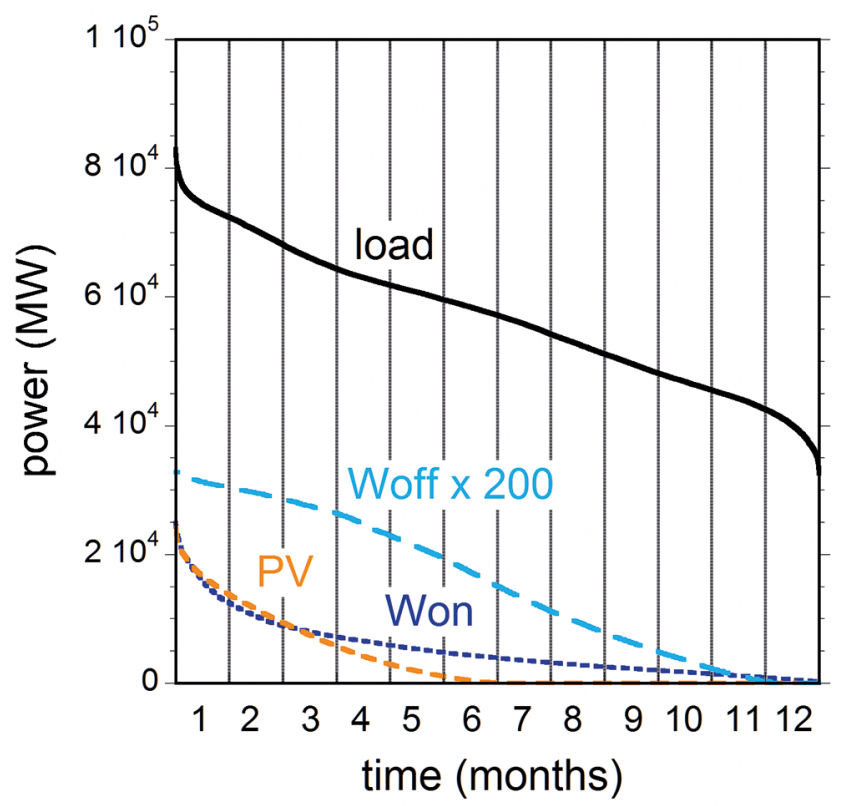

Fig. 2. Duration curves of the 2012 electricity production for Germany off the load (black) and the offshore wind $(\times 200$, dashed light blue), onshore wind (dotted blue) and solar PV (dashed orange) [2].

2) Construction of annual chronological series for the power of the load and the RE production. Time evolutions are obtained from real annual data, and levels are scaled to the quantities of annual energy of the reference case.

The following chapter presents the reference cases of the studies and describes the method.

\section{Method and data}

\subsection{References cases}

Five reference cases have been studied for which we assume different electrical mixes for Germany and France and refer to records of consumption and production in 2010, 2012 and 2013. While the annual consumption and production of the two countries differ greatly, there is little difference in one country from one year to another in spite of the different meteorological conditions. The rows in table 1 summarize the data of the five cases studied. The first column indicates 


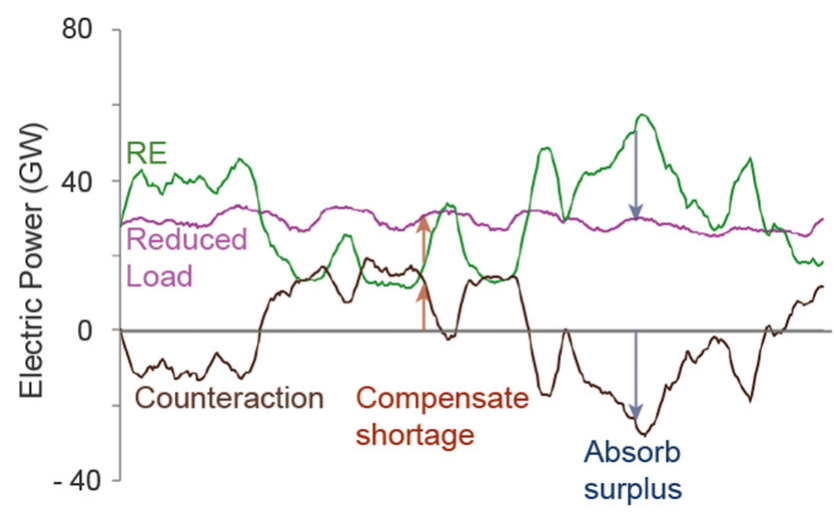

Fig. 3. Evolutions of power during one week: reduced load, RE (wind and solar). Counteraction (shortage compensation or surplus absorption) to match the load (reference case $100 \% \mathrm{RE}[3]$ ).

the country and the year. The second column gives the annual electric consumption and the next four columns the performance of wind and solar PV installations defined by the rated capacity and production. The next to last column gives the sum of RE (wind and solar) production.

The levels of power are measured in gigawatts (GW). The quantities of energy are measured in gigawatt-years $(\mathrm{GWy})$. One gigawatt-year is the energy delivered during a year by a source of constant power of one gigawatt. One gigawatt-year is equal to $8.76 \mathrm{TWh}$ (terawatt-hour). This makes possible a direct comparison of production to the rated capacity. Table 1 also provides the values of energy with the more familiar TWh units.

The last column gives the annual reduced load prescribed for the reference case. It is obtained by subtracting from consumption the carbon free production (hydroelectricity, nuclear and biomass). The values for the reference case are extrapolated from the data of column 1 using common assumptions regarding hydraulic and biomass productions that are assumed constant and assured. Hydroelectric production has reached its maximum extension. Further increase in biomass production for energy would preferably be devoted to biofuel rather than electricity production. As for nuclear production, different assumptions are made for Germany and for France. For Germany, nuclear production is not considered. For France, nuclear production is supposed to produce $50 \%$ of the electricity in the next decade according to the new French law of energy transition. Consumption is assumed to be constant or only slightly decreasing. Improved efficiency could further lower consumption, but growth in energy intensive applications (internet or electric cars) would lead to an increase.

As a result of these assumptions, the annual reduced loads for Germany are 64,2 GWy [1], 57,1 GWy [2] and 51,7 GWy [3]. For France, this gives annual reduced loads of 23.1 GWy [4] and 22.1 GWy [3].

\subsection{Chronological series}

The chronological series of consumption and productions are those of the respective year indicated in the first column of table 1. The chronological series are scaled up or down to the new target defined in the reference case. The reduced load consists of discrete values of power for each half hour of the year. The annual reduced load corresponds to the energy produced over the year.

Figure 3 shows one week in the chronological series for the last line of table 1, France [3].

The green curve indicated by RE is the power of the sum of Renewable intermittent Energies (wind and solar $\mathrm{PV})$. The variations in time of power of wind and solar production follow those of 2013 and are scaled up to reach the annual production as requested by the annual reduced load. This case is named 100\% RE. The equality between the annual reduced load and the annual RE production does not guarantee continuous equality, as shown by fig. 3; large oscillations of RE production above or below the reduced load (purple curve) are observed and lead to periods of surplus and shortage. This mismatch between the production from intermittent renewables and the reduced load requirement must be neutralized in order to meet the demand. To do this, a counteractive power (the black curve of fig. 3) should be added to the RE power. The counteractive power can be positive or negative and is produced by different types of counteractive systems according to the sign of the power:

- Positive: a backup which provides additional power to compensate for the shortage of RE production.

- Negative: an absorption which removes the RE surplus.

The integration over time of the positive power periods gives the annual energy shortage that must be compensated. Similarly the integration of negative power periods gives the annual energy surplus to be removed. In the $100 \% \mathrm{RE}$ case, accumulated surplus and shortage energies are equal at the end of the year. 


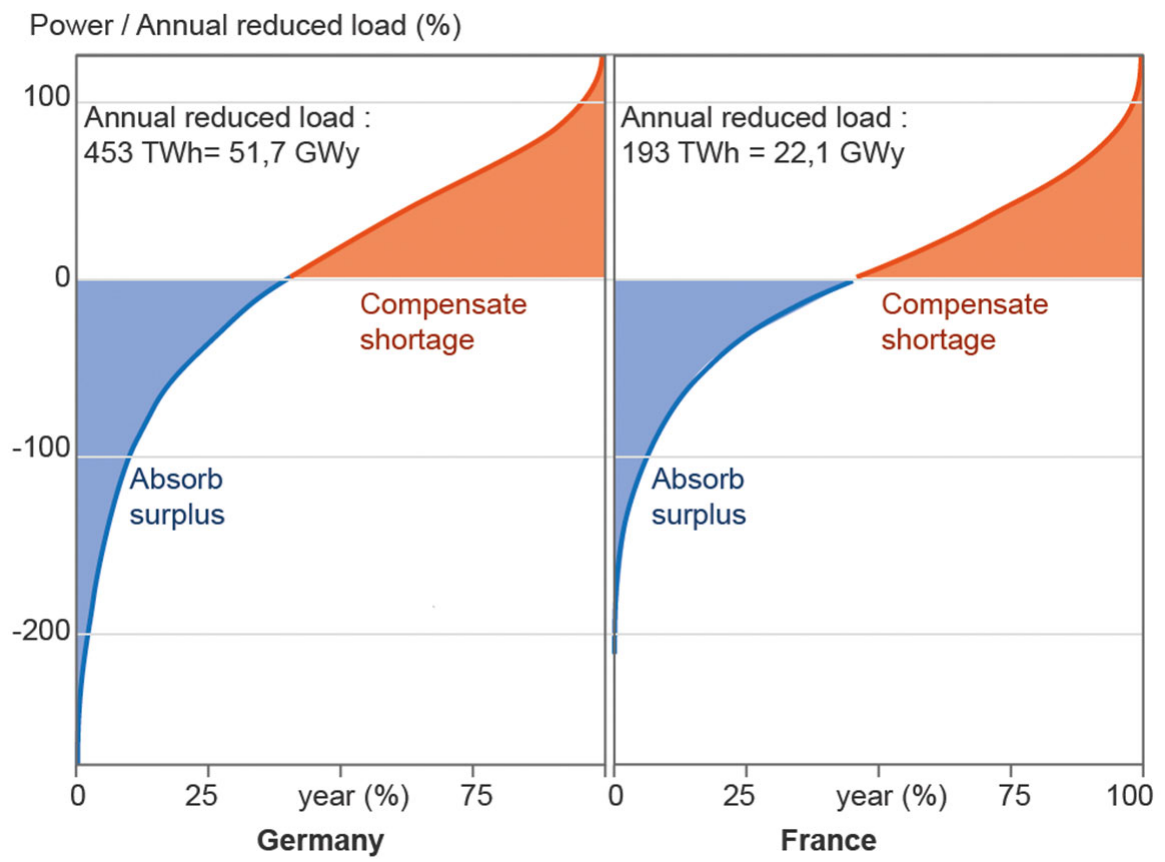

Fig. 4. Counteraction duration curves for France and Germany 2013.

Any combination of solar and wind (mix) can meet the requirement of a given annual RE production. However, depending on the share between wind and solar PV, the power chronological series are different and give, by integration over the year, different values of the energy shortage. Only one mix, the optimal mix, gives the minimal energy shortage. Obtained independently for each of the five studies, the results converge on a mix where PV represents roughly $20 \%$ of the total RE production. This optimal mix is typical of the temperate climate of Europe. Solar has the lowest share because it occurs only during daylight, and production is maximal in summer when the demand for electricity is lowest. The proportion between onshore and offshore wind does not change the results much and would result from legislative, economic and environmental constraints [2]. The studies assume that about one-third of wind production is offshore.

\section{Results}

\subsection{Annual production of RE equal to the load}

In this section, we consider the $100 \% \mathrm{RE}$ case, when RE produce the amount of the annual reduced load and the yearly counteraction energy is zero. But the instantaneous values of counteraction display large positive and negative fluctuations around the average in order to neutralize the mismatch between the load and the intermittent solar and wind energies, as shown by fig. 3. A duration curve is deduced for counteraction by sorting the calculated discrete power values in increasing order. Figure 4 presents the counteraction duration curves for Germany and France. In order to compare the two situations with the assumed different annual loads [3] the power values are scaled with the annual reduced load: 51,7 GWy for Germany and 22,1 GWy for France ${ }^{1}$.

The two duration curves are similar in shape and extent. Each duration curve has a negative branch and a positive branch. The negative branch corresponds to time intervals when the absorption must remove the surplus of RE production. The positive branch corresponds to time intervals when the backup must compensate for the shortage of RE production. These events alternate during the year as shown in a sample for one week in fig. 3 . The area of the negative branch measures the amount of electricity to be removed in a year by absorption means; the area of the positive branch gives the amount of electricity to be produced in a year by the backup sources. Periods of surplus and shortage require different means of storage, production or exchange that are described below. The total surplus and shortage per year are equal (by construction of the $100 \%$ RE case) and amount to approximately one-fourth of the annual reduced load. Thus, the absorption and backup would have to manage a large amount of electrical energy.

\footnotetext{
1 This operation is numerically exact when energy is expressed in Gigawatt-years (GWy). In this unit, the annual reduced load (energy) is equal to the average reduced load power multiplied by 8760 , the number of hours of a regular year.
} 


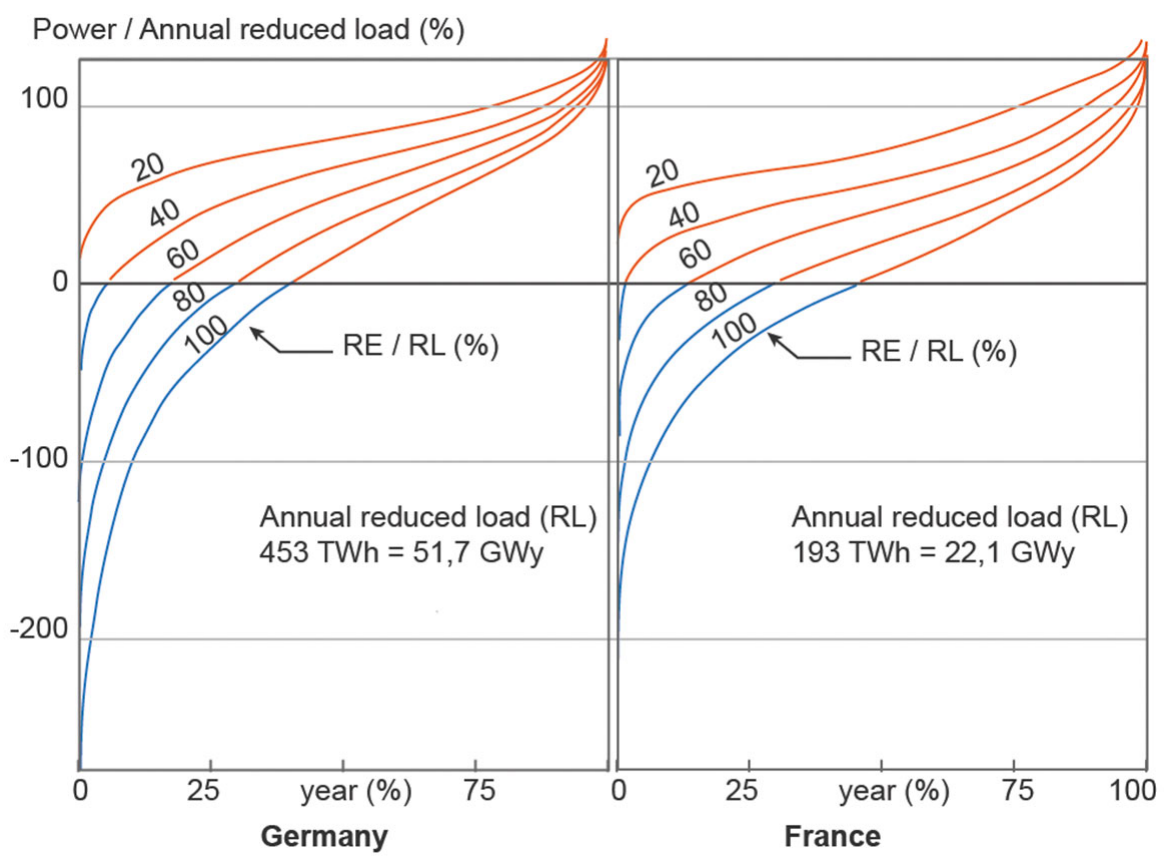

Fig. 5. Counteraction duration curves for various RE shares of the annual reduced load (RL) 2013 [3].

Moreover, these installations would have to handle high levels of power. The removal of surplus requires $250 \%$ of the average annual reduced load power and the compensation for shortages $120 \%$.

With the annual reduced load as a scaling factor, the duration curves and values of energy and power associated with show common trends, at least within the range of situations considered here, that are useful for further studies.

\subsection{Lower contributions of RE to the load}

This section looks at the cases where the production of RE over the year is a fraction of the annual reduced load (RL): 20\%, 40\%, 60\% or 80\%. Results for France and Germany [3] are presented in fig. 5. The two graphs are families of duration curves parameterized by the ratio $\mathrm{RE} / \mathrm{RL}$ (RE production divided by the annual reduced load, RL).

In the $20 \%$ case, the backup system is continually called upon to produce the necessary complement to the RE. From $40 \%$ to $100 \%$, backup production is needed only during part of the year. The time during which it is needed decreases as the RE share increases. Since hydro, nuclear and biomass productions are already included to cover the full load, the backup production can be provided by fossil fuels only. The drawback is the emission of $\mathrm{CO}_{2}$. The maximum value of a duration curve indicates the power capacity to be installed to manage the peak load: $120 \%$ of the annual load, independently of the share of RE. The area under the positive branch of the duration curve, i.e. the electricity produced by fossil fuels, diminishes with an increasing share of RE. This has two consequences: one positive, lowering the emissions of $\mathrm{CO}_{2}$ and one negative, lowering the load factor of the installation and the financial gain.

Negative values of counteraction appear at $40 \%$ of the RE/RL ratio in both countries, showing periods when the surplus must be absorbed by specific means, which are described below. This is an important result common to the two countries.

These results are summarized in fig. 6. In each graph, the horizontal axis represents the percentage of RE in the annual reduced load, and the vertical axis represents an annual quantity of energy as denoted in the graphs divided by the annual reduced load.

Four curves are displayed for each country.

- The production of RE divided by the annual reduced load (RL): It is equal to the abscissa and thus it follows the first bisector (RE produced).

- The absorption needed for surplus removal: It is zero for an RE share lower than 40\%, and it increases with the percentage of RE. For $100 \%$ RE it amounts to $23 \%$ (France) or $27 \%$ (Germany) of the load.

- The RE production used immediately: It is equal to the production of RE when RE is less than $40 \%$ of RL and it diverges from the RE production when RE/RL increases. The deviation is equal to the surplus removal but could be reduced through absorption valorizing part of the surplus. 


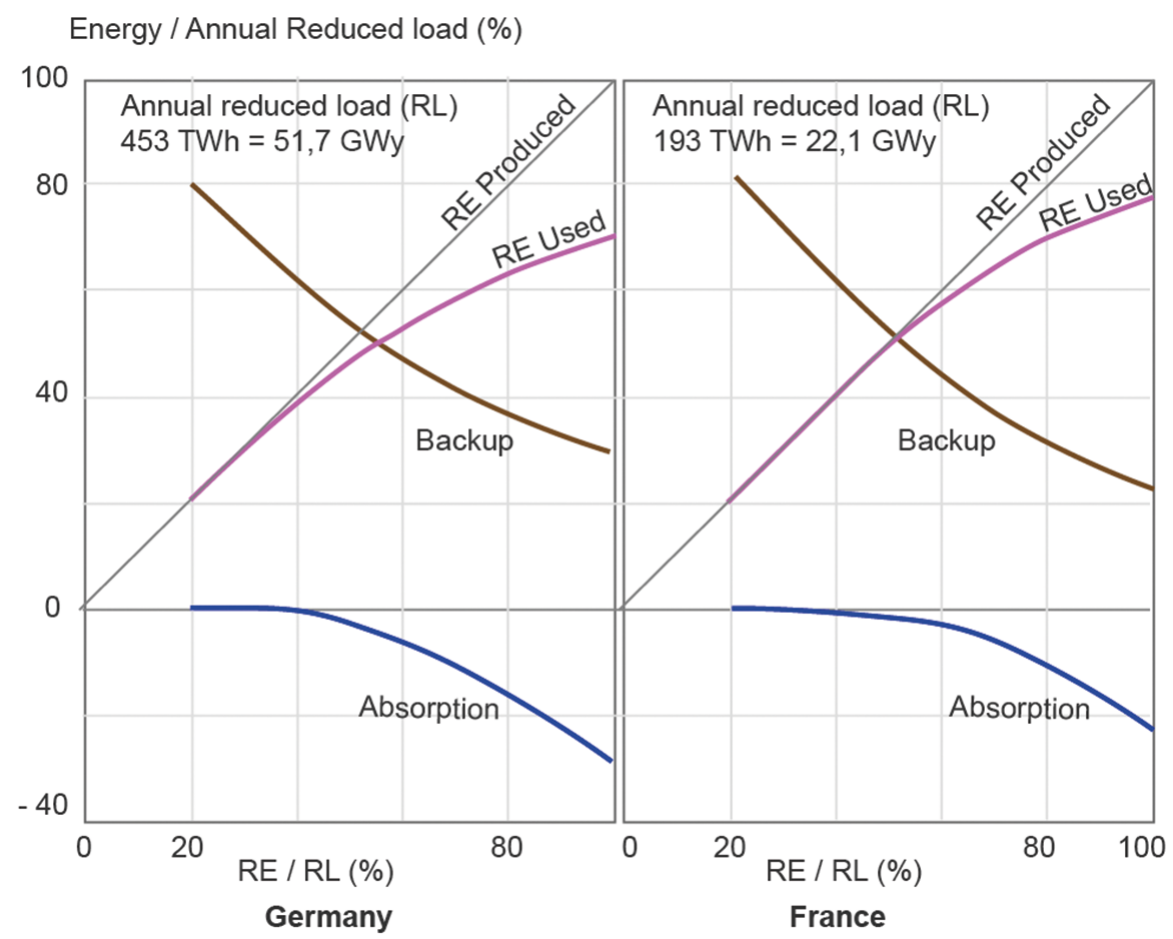

Fig. 6. RE produced and used immediately, annual energies from absorption and backup versus the ratio of RE to the annual reduced load (RL).

Table 2. Annual reduced load (GWy); Electricity mix giving the installed power capacities IP (GW) and annual production (GWy) for wind, solar and backup; RE production used immediately (GWy) and total installed capacity (GW).

\begin{tabular}{|l|c|c|c|c|c|c|c|c|c|c|c|}
\hline $\begin{array}{l}\text { Prod. GWy } \\
\text { IP GW }\end{array}$ & $\begin{array}{c}\text { Reduced } \\
\text { load }\end{array}$ & \multicolumn{2}{|c|}{$\begin{array}{c}\text { Wind } \\
\text { onshore }\end{array}$} & \multicolumn{2}{|c|}{$\begin{array}{c}\text { Wind } \\
\text { offshore }\end{array}$} & \multicolumn{2}{|c|}{ Solar PV } & \multicolumn{2}{|c|}{$\begin{array}{c}\text { Backup } \\
\text { RE }\end{array}$} & $\begin{array}{c}\text { Total } \\
\text { IP }\end{array}$ \\
\hline Study & GWy & IP & Prod & IP & Prod & IP & Prod & IP & Prod & GWy & GW \\
\hline Germany [1] & 64.2 & 191 & 33.6 & 44 & 16.8 & 99 & 13.8 & 84 & 17.5 & 46.7 & 418 \\
\hline Germany [2] & 57.1 & 175 & 30.9 & 33 & 15.4 & 97 & 10.7 & 73 & 15.0 & 42.1 & 388 \\
\hline Germany [3] & 51.7 & 140 & 28.1 & 32 & 14.0 & 87 & 9.6 & 83 & 15.2 & 36.5 & 342 \\
\hline France [4] & 23.1 & 50 & 11.9 & 19 & 6.6 & 35 & 4.6 & 42 & 5.5 & 17.6 & 146 \\
\hline France [3] & 22.1 & 53 & 12.1 & 15 & 6.1 & 30 & 3.9 & 35 & 5.0 & 17.1 & 133 \\
\hline
\end{tabular}

- The backup needed for shortage compensation: When added to the RE used, the total gives 100\% of RL. Thus, the backup decreases as the RE/RL increases. However, it does not fall to zero at $100 \% \mathrm{RE}$, and a minimum of $23 \%$ to $27 \%$ of backup is still needed.

\subsection{Mix for RE $100 \%$ share and installed capacities}

The results obtained with the scenarios defined in [3] and the support of chronological series from 2013 show a great similarity with the previous studies, [1] and [2] for Germany and [4] for France. Table 2 gives the main results of the five cases, for a share of RE equal to $100 \%$ of the reduced load. The first column gives the annual reduced load (already shown in the last column of table 1). The other columns give the installed capacities and the annual productions of onshore and offshore wind, solar PV and backup. The next to last column lists the RE production used immediately and the last one the sum of installed capacities. These values are taken from the original publications and can vary according to the data and assumptions of the different studies. 
Table 3. Installed power and annual energy production of the sources of the mix.

\begin{tabular}{|l|c|c|c|c|c|c|c|c|c|c|c|}
\hline $\begin{array}{l}\text { Prod, IP } \\
\% \text { Load }\end{array}$ & $\begin{array}{c}\text { Reduced } \\
\text { load }\end{array}$ & \multicolumn{2}{|c|}{$\begin{array}{c}\text { Wind } \\
\text { onshore }\end{array}$} & \multicolumn{2}{|c|}{$\begin{array}{c}\text { Wind } \\
\text { offshore }\end{array}$} & \multicolumn{2}{|c|}{ Solar PV } & \multicolumn{3}{|c|}{$\begin{array}{c}\text { Backup } \\
\text { RE } \\
\text { used }\end{array}$} & $\begin{array}{c}\text { Total } \\
\text { IP }\end{array}$ \\
\hline Studies & & IP & Prod & IP & Prod & IP & Prod & IP & Prod & $\%$ & $\%$ \\
\hline Germany [1] & 100 & 298 & 52 & 69 & 26 & 154 & 22 & 131 & 27 & 73 & 652 \\
\hline Germany [2] & 100 & 307 & 54 & 58 & 27 & 170 & 19 & 145 & 26 & 74 & 680 \\
\hline Germany [3] & 100 & 271 & 54 & 62 & 27 & 168 & 19 & 161 & 30 & 71 & 662 \\
\hline France [4] & 100 & 216 & 53 & 82 & 29 & 151 & 20 & 181 & 24 & 76 & 629 \\
\hline France [3] & 100 & 240 & 55 & 68 & 28 & 136 & 18 & 158 & 23 & 77 & 602 \\
\hline Average & $\mathbf{1 0 0}$ & $\mathbf{2 6 6}$ & $\mathbf{5 3}$ & $\mathbf{6 8}$ & $\mathbf{2 7}$ & $\mathbf{1 5 6}$ & $\mathbf{1 9}$ & $\mathbf{1 5 5}$ & $\mathbf{2 6}$ & $\mathbf{7 4}$ & $\mathbf{6 4 5}$ \\
\hline
\end{tabular}

Wind and solar productions are evaluated first from the optimal mix, which minimizes the backup production in each case studied, as explained in paragraph 2.2. Installed capacities are calculated from the measured values of the load factor (ratio of the yearly production of energy to the energy which would have been produced at nameplate power). The values of the load factor may slightly differ from one country to the other but are remarkably stable over the years (Onshore wind: 20\% in Germany and 23\% in France. Solar PV: 11\% in Germany and 13\% in France). For offshore wind, measurements are still scarce and therefore are not as reliable as those for onshore wind or solar PV. Load factor values assumed in the studies range from $35 \%$ to $45 \%$. For backup production, the installed capacity must be slightly higher than the peak value of the duration curve to guarantee electric supply from installations that are not always available.

\section{Main results}

\subsection{A common configuration}

Figure 6 has shown great similarity in the results for both countries when the annual reduced load is used to normalize energy of the surplus and shortage. Table 3 is also obtained through a division of energy productions of table 2 by the annual reduced load (second column of table 2). The results, given in table 3, are expressed as a percentage of the annual reduced load. The installed power can also be divided by the annual reduced load measured in GWy, because the annual energy and mean power have the same values in this unit. The results of the different rows, percentages of the annual reduced load, are very similar in spite of the difference in countries and the years of data collection. The bottom row gives their averages.

Figure 7 illustrates these results using the analogy of a balance: it weighs the energy produced, represented by the colored areas of the vertical bars. Their height is the percentage of the annual reduced load measured along the vertical axis.

The left pan of the scale supports the production of energy distributed depending on its origin (wind, solar and backup). The total height of the bars (colored and uncolored) represents the installed capacities and the colored part the energy produced. The right pan supports the energy produced, divided into two parts: the part immediately used to cover the load (horizontal line at $100 \%$ ) and a surplus of $26 \%$. The drawing represents the average of the studies, as shown in table 3. The horizontal marks show the dispersion of the results of the five studies around their average. For the energies produced, the results are so close to the average that they are hardly distinguishable. A greater dispersion is observed for the installed capacities, due to the differences in the capacity factors for wind and solar energy between the countries, to small deviations of the optimal mix around $20 \%$ of PV, and to different assumptions for the availability factor of backup installations (80\% or 100\%).

However, the dispersion of the results is small, and the following conclusions can be drawn immediately: In order to maintain equilibrium in the balance and in the grid, the energy production must reach $126 \%$ of the annual reduced load. The surplus of $26 \%$ appearing in the intermittent production of wind and solar energies must be compensated by an addition of $26 \%$ produced with a backup system. The capacity factors are low for the backup as well as for the intermittent sources. This electrical mix requires large investments in installations that would be used only for short and discontinuous periods. 


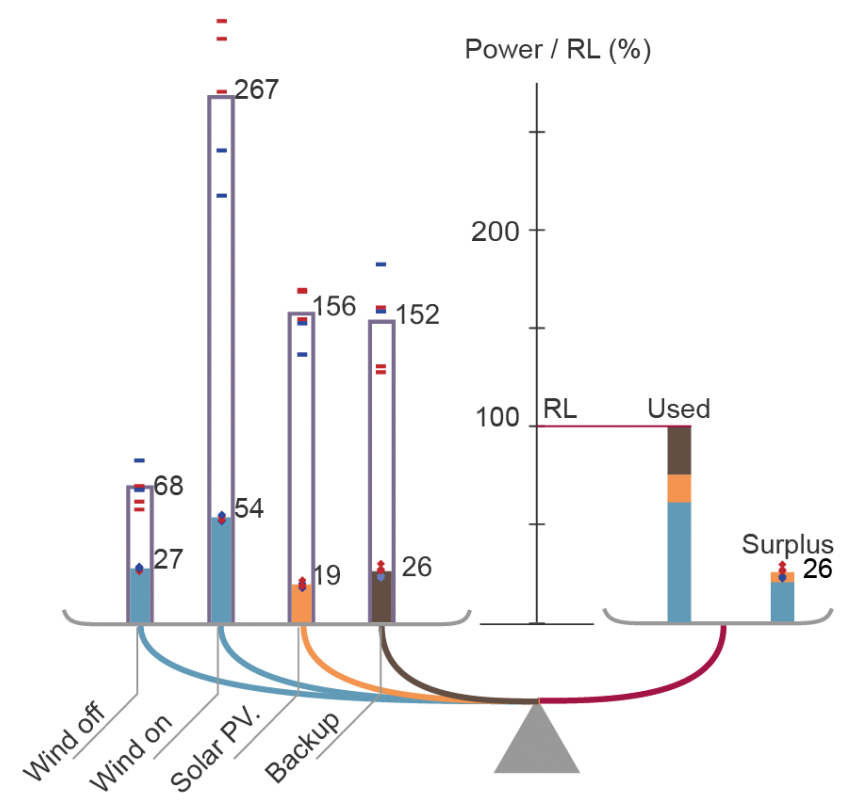

Fig. 7. Balance of energy for the $100 \%$ RE case. Installed power (total bars) and average power (filled bars) produced (left side). Production used and surplus (right side). Average of the five studies shown by the dots (Germany in red and France in blue).

\subsection{Counteractive measures}

Adjusting consumption. It is often proposed to adjust the time of consumption (to delay or anticipate some uses of electricity) in response to the constraints of RE production. Smart grids are thought to be the appropriate technology. But the variations are not of the same order of magnitude, as shown in fig. 1. The adjustment of consumption would be a second order correction of the intermittency. Smart grids can help in load management in the range of its power variations. Trying to adjust the consumption to RE would be much more difficult when power variations are of another order of magnitude, more than ten times greater. More can be found on the subject for Germany in [2].

Developing storage. Storage capacities could stock electricity when RE production exceeds the load and feed the grid with electricity when RE do not produce enough. The storage capacities needed to deal with the surplus are very high and well above the existing or foreseeable capacities in both countries. In Germany, if RE supplied $100 \%$ of the annual reduced load ( $85 \%$ of consumption), $33 \mathrm{TWh}$ would have to be stored, a value more than 500 times higher than the present capacity [2]; the maximum power would reach $150 \mathrm{GW}$. In France [3], if RE supplied $100 \%$ of the annual reduced load (35\% of consumption), the capacity of the storage needed would be 14 TWh, a value 200 times larger than the present capacity; the maximum power would have to be $45 \mathrm{GW}$.

As shown by figs. 1 and 3, three types of storage would be needed: daily, weekly and seasonal. The daily and weekly storage are needed to transfer between the highs and lows of production and consumption, between day and night, and between workdays and weekends. The seasonal storage would take care of the variations of longer periods. In any case, electricity is never stored directly, but is always transformed into another form of energy (mechanical, magnetic or chemical). Filling and emptying the storage require two separate operations accompanied by losses, which can vary from $20 \%$ in the best case (hydraulic storage) to $70 \%$ in chemical storage. Thus, only part of the surplus would be recovered. For periods less than a week, mechanical storage is preferred for its higher efficiency (losses ranging from $20 \%$ with hydraulics to $45 \%$ with compressed air). For seasonal storage, the solution is the production of methane obtained from hydrogen produced by electrolysis combined with $\mathrm{CO}_{2}$. The process is not industrial yet but at a demonstration stage. The overall efficiency would be $33 \%$ : two-thirds of the surplus electricity would be lost.

Importing or exporting electricity. Importing or exporting electricity could be a third way to return to equilibrium during the periods of shortage or surplus, by exchanges between the two countries and with their neighbors. Even after increasing the number of power lines across the borders, it will remain limited. Roughly in the same time zone, the two countries and their close neighbors are also exposed to atmospheric conditions with high and low pressure systems that cover an area larger than the countries. Thus the countries subjected to similar windy or calm conditions will also have the same need to export electricity during the surplus periods or import it during periods of shortage. If the two countries reach similar levels of RE, their exchanges of electricity will stagnate.

Using surplus. Adjusting consumption, developing storage and importing or exporting electricity are the only three means to use the surplus. Adjustment of consumption or exchange of electricity with neighbors would use only a 

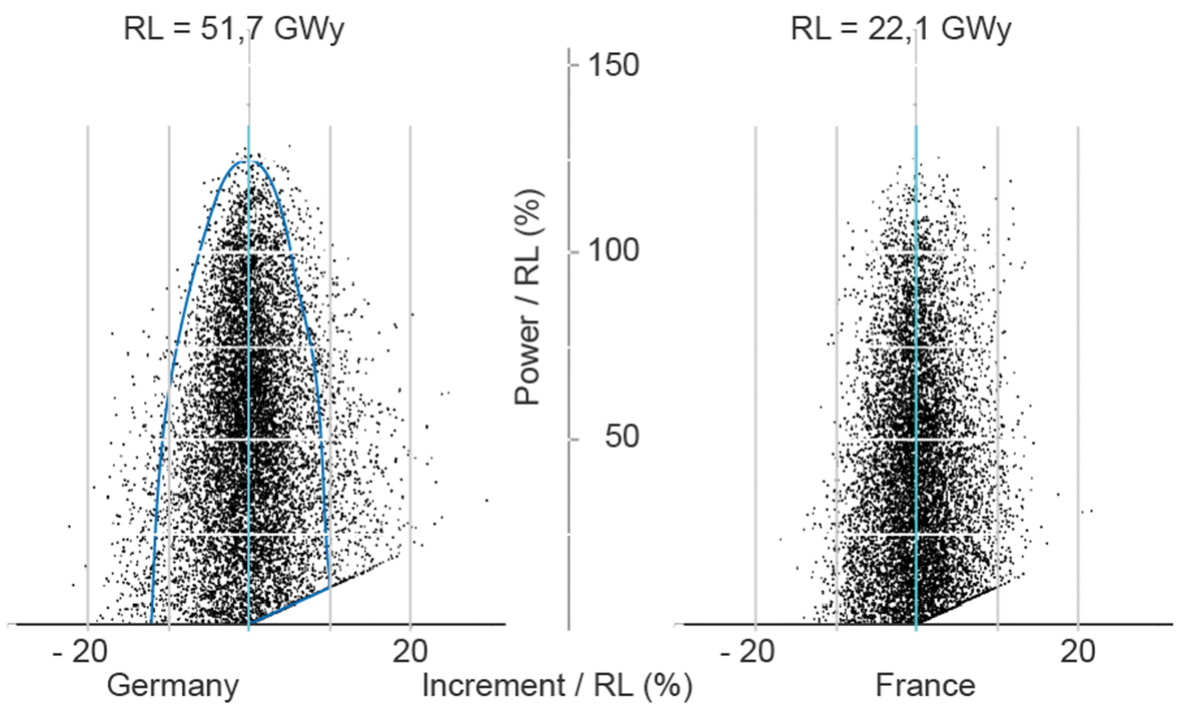

Fig. 8. Black dots: power variations during time intervals of $30 \mathrm{~min}$. Blue line: envelope of the power variation set for $15 \mathrm{~min}$ time intervals.

very small fraction. Huge storage capacities should be developed to collect the rest. No great development of hydraulic storage can be expected. Thus the production of hydrogen and methane could be the candidate for this huge investment. However, the low efficiency of the process leads to the loss of two-thirds of the electrical surplus. One can expect a reluctance to develop great storage capacities under these conditions, and it is probable that nearly all the surplus would be lost or used for other purposes, like heating. Today the share of RE is much lower, but negative prices of electricity already appear during periods of large wind production in Denmark and Germany. This indicates the trend. Another measure, which requires changing the rules for renewable energies, would be to reduce excessive wind or solar productions $^{2}$.

Compensating shortage. Fossil fuels constitute the only solution of production remaining during the periods of shortage. Gas turbines can start quickly and are suitable to following the fast transients. The drawback is the emission of $\mathrm{CO}_{2}$, which is quantified in the four studies [1] to [4]. Combustion of gas emits less $\mathrm{CO}_{2}$ than do other fossil fuels. However, methane is a greenhouse gas whose impact ${ }^{3}$ over a century is 25 times higher than the one of $\mathrm{CO}_{2}$. If there are leakages (during extraction, production and transportation) that amount to $4 \%$ of the gas used, the total chain of supply and production with gas has the same impact on climate change as burning coal. This additional effect is not included in studies [1] to [4] but it reinforces their conclusions. Finally, RE can reduce $\mathrm{CO}_{2}$ emissions only when they replace fossil fuels and as long as the RE share in the mix is low. But, with an increasing share of RE, $\mathrm{CO}_{2}$ emissions could stall or rise as gas and coal plants are used for the backup. The emission of $\mathrm{CO}_{2}$ is in all cases greater than that obtained in countries with an electrical mix based on nuclear and hydroelectricity in large shares: Sweden, France and Switzerland.

\subsection{Power transients}

Figures 1 and 3 give an insight into the operational conditions of the counteraction system and the transients of power it must follow. The studies referenced in this paper show rapid alternations between periods of surplus and periods of shortage: a yearly average of 1.4 times per day [3]. It is a challenge for the counteraction installations to follow the transients and for the grid operator to coordinate the installations and maintain the equilibrium of the grid.

Figure 8, from [3], illustrates this with a scatter plot for the counteraction power. Each point corresponds to an average recorded every $30 \mathrm{~min}$ during the year. The vertical axis gives the power and the horizontal axis its increment from the previous half-hour. The power is dimensionless, a percentage of the annual reduced load power. The results for the two countries show again remarkable similarities: an increase of $10 \%$ of the reduced load within $30 \mathrm{~min}$ is not rare ( $\pm 5 \mathrm{GW}$ in Germany and $\pm 2 \mathrm{GW}$ in France). The blue line in the graph for Germany is the envelope of the results of the study [2] done with a time step of $15 \mathrm{~min}$. The similarity of the results obtained with the two time steps indicates the stochastic character of the power changes that the counteraction must accommodate (leading to $\pm 5 \mathrm{GW}$ in 15 min or less).

\footnotetext{
2 A technically simple way is to remove intermittent sources temporarily from the grid. However, this operational concept gives rise to economic problems which are already obvious in Germany. Substantial subsidies are paid to compensate for periods of excess power when wind turbines are shutdown.

${ }^{3}$ Radiation forcing.
} 


\subsection{Investments}

Table 2 and fig. 7 indicate the capacities to be installed to meet the production needed in the $100 \%$ RE mix. The total power of the installed capacities amounts to six times the annual reduced load. Consequently, the average load factor (ratio of the yearly production of energy to the energy which would have been produced at full power) is less than $17 \%$ for the installations of the mix. The load factors of wind and solar are the results of natural phenomena that obviously cannot be changed. The load factors of the other installations, those of the counteraction that must follow the transients, are much lower than under the condition of unrestricted continuous operation. Adapting to the intermittency will perturb the economic model of the backup producers, who would have to maintain operational capacities far below their potential: a problem that has already emerged.

Altogether, large investments must be made for installed capacities that will operate only a fraction of the time. The cost of renewable energies depends mainly on the investment, capital and interest rates, less on operational costs. Renewable energies also require land area for the installations. Land area and investment costs can be found in studies [2] to [5] for Europe. For both land area and financing, construction will have to deal with social and economic realities.

\section{Discussion and perspectives}

Starting from different energy mixes for Germany and France and different years of production of renewable intermittent energies (RE), the five studies presented in this paper reveal strong similar trends, which would have to be considered when increasing the share of intermittent energies in the electricity mix.

There is an optimal distribution between solar PV and wind that minimizes the negative consequences of intermittency in the moderate climate of Europe. It corresponds to $20 \%$ of the annual RE production provided by solar $\mathrm{PV}$. The ratio of onshore and offshore wind is of little influence for the performance but defines the power capacity to be installed. The choice would result from other factors, like technical difficulties, cost, and environmental and social constraints. The studies assume that the offshore contribution is about one-third of the wind production.

The intermittent production does not match the load, and a counteraction system has to be implemented to restore equilibrium. When RE provides only $20 \%$ of the annual reduced load, the shortage must be filled by additional production to reach the reduced load. This production is done by fossil fuels since the other energy sources (hydraulic, biomass and nuclear) are already used in the definition of the reduced load. When RE reaches $40 \%$ of the annual reduced load, periods of surplus production appear and additional counteraction equipment, like storage, must be provided. This value of $40 \%$ is an estimate of the proportion of RE in the annual reduced load, where it becomes very difficult to manage the intermittency with the counteraction system. Indeed, already today with a percentage of RE of $18 \%$, occurrence of negative prices for electricity during periods of wind overproduction reveals the difficulty [2].

For an RE share of $100 \%$ of the annual reduced load, the annual surplus of energy rises to $26 \%$ of the annual reduced load. This surplus exceeds by far the foreseeable storage capacities in Germany and France. Only countries like Norway and Austria, with large hydraulic capacities (at least $50 \%$ of the load) could handle their surplus with pumped-storage hydroelectricity or other adjustable forms of hydroelectricity. In the case of Germany and France, most of the surplus would be dumped and would have to be replaced by an equivalent amount of electricity produced by fossil-fuel power stations. When renewables replace fossil fuel power stations, there would still be a decrease of $\mathrm{CO}_{2}$ emissions, although less than expected when the back-up is not taken into account. When they replace nuclear production, $\mathrm{CO}_{2}$ emissions will increase. In any case, $\mathrm{CO}_{2}$ emissions could not be lower, for a given electricity production, than those of countries with a large proportion of hydro and nuclear electricity in their mix (like Sweden, France and Switzerland).

The reference case of $100 \%$ of $\mathrm{RE}$ requires the investment in installations whose total rated capacities are six times greater than the average power delivered. The capacity factor for the mix would be a little less than $17 \%$. Today the average capacity factor for existing installations is higher than $50 \%$. The extension of wind and solar intermittent productions of low capacity factors (respectively $23 \%$ and $12 \%$ ) forces all power installations used as backup to operate at low capacity factors. This leads to larger rated capacity needed for the same output and raises questions about the economy of the system as already observed in countries with larger shares of wind and solar power per inhabitant causing high consumer prices for electricity (Denmark, Germany, Spain). A high penetration of RE also raises the environmental and socio-economic questions of the land devoted to their production.

Decentralized wind and solar power would also require an extension of the grid to collect and transport electricity and the installation of distributed control systems for production sources and consumer devices. These other investments would also have to be financed.

The counteraction installations would have to follow transients with large power variations over short time intervals. Present studies use time intervals of 30 or $15 \mathrm{~min}$, much longer than the response time for grid control. The constraints on the management of the grid would be higher than what is shown by the quantitative results of power variations shown here. The real time decisions between starting, stopping or varying the power of available sources, varying consumption, exporting or importing electricity (all operations limited by their internal constraints) would be very complex and subject to errors which must be avoided by all means. 
To conclude, the installation of renewable intermittent energy sources on the grid cannot be done without being fully aware of the consequences as presented in this study. At least three conditions must be fulfilled: the service of the electrical network must be guaranteed; $\mathrm{CO}_{2}$ emissions from the electricity sector must decrease; any transition must be done in a socially responsible and economical way.

Open access funding provided by Max Planck Society (or associated institution if applicable). The authors thank Martha Grand for her aid in the translation of the original French version and her contribution to the edition of the present article. The authors would like to thank the referee for her/his constructive comments.

Open Access This is an open access article distributed under the terms of the Creative Commons Attribution License (http://creativecommons.org/licenses/by/4.0), which permits unrestricted use, distribution, and reproduction in any medium, provided the original work is properly cited.

\section{References}

1. F. Wagner, Feature of an electricity supply system based on variable input, IPP Report 18/1 (2012).

2. F. Wagner, Eur. Phys. J. Plus 129, 20 (2014).

3. D. Grand, C. Le Brun, R. Vidil, Intermittence des énergies renouvelables et insertion dans le mix électrique Exemples de la France et de l'Allemagne, in Techniques de l'ingénieur (juillet 2015) IN301.

4. D. Grand, C. Le Brun, R. Vidil, Transition énergétique et mix électrique: les énergies renouvelables peuvent-elles compenser une réduction du nucléaire, in La Revue de l'Energie, Vol. 619 (2014).

5. F. Wagner, Eur. Phys. J. Plus 129, 219 (2014). 